CLINICAL STUDY

\title{
Ketoconazole revisited: a preoperative or postoperative treatment in Cushing's disease
}

\author{
F Castinetti, I Morange, P Jaquet, B Conte-Devolx and T Brue \\ Department of Endocrinology, Diabetes, Metabolic Diseases and Nutrition, Hôpital de la Timone, Centre Hospitalier Universitaire de Marseille and Faculté \\ de Médecine, Université de la Méditerranée, 264 rue St Pierre, Cedex 5, 13385 Marseille, France
}

(Correspondence should be addressed to T Brue; Email: thierry.brue@mail.ap-hm.fr)

\begin{abstract}
Context: Although transsphenoidal surgery remains the first-line treatment in Cushing's disease (CD), recurrence is observed in about $20 \%$ of cases. Adjunctive treatments each have specific drawbacks. Despite its inhibitory effects on steroidogenesis, the antifungal drug ketoconazole was only evaluated in series with few patients and/or short-term follow-up.

Objective: Analysis of long-term hormonal effects and tolerance of ketoconazole in CD.

Design: A total of 38 patients were retrospectively studied with a mean follow-up of 23 months (6-72). Setting: All patients were treated at the same Department of Endocrinology in Marseille, France.

Patients: The 38 patients with CD, of whom 17 had previous transsphenoidal surgery.

Intervention: Ketoconazole was begun at $200-400 \mathrm{mg} /$ day and titrated up to $1200 \mathrm{mg} / \mathrm{day}$ until biochemical remission.

Main outcome measures: Patients were considered controlled if 24-h urinary free cortisol was normalized.

Results: Five patients stopped ketoconazole during the first week because of clinical or biological intolerance. On an intention to treat basis, $45 \%$ of the patients were controlled as were $51 \%$ of those treated long term. Initial hormonal levels were not statistically different between patients controlled or uncontrolled. Ketoconazole was similarly efficacious as a primary or postoperative treatment. Among 15 patients without visible adenoma at initial evaluation, subsequent follow-up allowed identification of the lesion in five cases. No adrenal insufficiency was observed. Adverse effects were rare in patients treated long term.

Conclusions: Ketoconazole is a safe and efficacious treatment in CD, particularly in patients for whom surgery is contraindicated, or delayed because of the absence of image of adenoma on magnetic resonance imaging.
\end{abstract}

European Journal of Endocrinology 158 91-99

\section{Introduction}

Adrenocorticotropin (ACTH)-dependent Cushing's syndrome may be caused by a pituitary corticotroph adenoma (Cushing's disease (CD), 80-85\% of cases), by an extrapituitary tumor (ectopic ACTH syndrome), or very rarely by a corticotrophin-releasing hormone (CRH)-secreting tumor (ectopic CRH syndrome). At the time of diagnosis, because of signs and symptoms of chronic endogenous glucocorticoid excess, most corticotroph adenomas are microadenomas ( $<10 \mathrm{~mm}$ in largest diameter). Complications of CD include hypertension, hypertrophic cardiomyopathy, diabetes, obesity, hyperlipidemia, osteoporosis, psychiatric, and cognitive manifestations (1).

Transsphenoidal surgery usually represents the firstline treatment of $\mathrm{CD}$. In series reported by experienced surgeons, immediate success rates vary from 64 to $93 \%$. Recurrence, frequently observed 5-10 years after surgery, occurs in $9-25 \%$ cases $(2-4)$. Various treatments for recurrence have been proposed, but each of them implies specific risks: Nelson's syndrome after bilateral adrenalectomy (5), hypopituitarism, and radiation-induced brain tumors after radiotherapy $(6,7)$. Gamma Knife radiosurgery, though responsible for fewer adverse effects, is only effective in about $40-50 \%$ of cases $(8-10)$.

Several medical treatments have been proposed in CD: despite its effectiveness, mitotane therapy is complicated by several side effects (11-13); metyrapone, which was mainly used in combination with aminoglutethimide, frequently induces hyperandrogenism $(14,15)$; only a small percentage of patients with $\mathrm{CD}$ is in remission with bromocriptine (15); and efficacy of glitazones is still a matter of debate with contradictory results in previously published series (16-18).

Ketoconazole is an antifungal agent with steroidogenesis inhibitor effects linked to inhibition of cytochrome P450 enzymes $(19,20)$. In addition to its blocking effects on steroidogenesis, ketoconazole has putative 
extra-adrenal actions. At high concentrations, it has been shown to be an antagonist of the glucocorticoid receptor in cultured hepatoma cells (21) and it binds to glucocorticoid receptors in cytosolic preparations of human mononuclear cells (22). Earlier studies and case reports have described its effects in a total of about 100 patients, including 85 patients with CD (23-29). However, published studies were always based on few patients $(<10)$ except one on 28 patients with $\mathrm{CD}$ previously treated with conventional radiotherapy (30). Moreover, all but one study had short mean follow-up not exceeding 8 months (31). We retrospectively studied the efficacy and adverse side effects of ketoconazole in 38 patients with $\mathrm{CD}$, with a mean follow-up of 23 months.

\section{Patients and methods}

A total of 38 patients with active CD were treated with ketoconazole between 1995 and 2005 at the Department of Endocrinology of the University Hospital La Timone (Marseille, France). The diagnosis of CD was based on the association of clinical features of the disease, elevated 24-h urinary free cortisol level (UFC; mean of three samples to control for variability in cortisol secretion or urine collection), elevated serum cortisol and ACTH levels with a lack of response to a standard low-dose dexamethasone suppression test ( $2 \mathrm{mg}$ /day for 2 days), and appropriate response to high-dose dexamethasone test ( $8 \mathrm{mg}$ /day for 2 days). In the absence of an unequivocal image of pituitary adenoma at magnetic resonance imaging (MRI), inferior petrosal sinus sampling was performed. As ketoconazole is not currently approved in this indication in France, informed consent was obtained from each patient. All patients had received detailed information on side effects and potential benefits of ketoconazole used in a condition different from that of the marketed indication and had given an informed consent form allowing retrospective studies to be performed on their medical records for scientific purposes, as approved by the Ethics Committee of our institution.

Each patient had a complete clinical and hormonal evaluation before ketoconazole including 0800 and $0000 \mathrm{~h}$ ACTH and cortisol, and $24 \mathrm{~h}$ UFC. Plasma ACTH, cortisol, and UFC were measured by commercial RIA kits (Beckman-Coulter-Immunotech, Marseille, France). The ACTH immunoradiometric assay had a sensitivity of $1.2 \mathrm{pg} / \mathrm{ml}$ (at 95\% probability), and intraand inter-assay coefficients of variation of $6.9-9.1 \%$ and $6.2-9.6 \%$ respectively. The cortisol assay had a sensitivity of $10 \mathrm{nmol} / \mathrm{l}$, and intra- and inter-assay coefficients of variation of $2.8-5.1 \%$ and $5.3-9.2 \%$ respectively.

Three patients had previously been treated by Gamma Knife radiosurgery before initiation of ketoconazole treatment. We divided the whole population in two groups: those who were not treated surgically before ketoconazole called 'No pituitary surgery group' and the others who had ketoconazole as an adjunctive treatment called 'After pituitary surgery group'.

Treatment with ketoconazole was always initiated at low dose (200-400 mg/day) with weekly control of aspartate aminotransferase (ASAT), alanine aminotransferase (ALAT), and $\gamma$-glutamyl transpeptidase $(\gamma-\mathrm{GT})$ during the first month. The first evaluation of UFC (mean of three samples) was carried out after 1 month of treatment: if necessary, the dose of ketoconazole was increased by $200 \mathrm{mg}$ per day every 10-15 days, with weekly liver function test controls. Urinary cortisol secretion was monitored until normalization at 1-4 month intervals, and ketoconazole dose was increased up to $1200 \mathrm{mg} /$ day if necessary. Complete clinical evaluation was also periodically performed (clinical signs of hypercortisolism, weight, blood pressure) as well as standard biological evaluations including blood glucose and liver function tests (repeated at each titration step). Patients were considered controlled if they had normal 24-h UFC at two consecutive determinations. When the dose of ketoconazole was correct, hormonal control was checked at 3-month intervals. Patients who had immediate clinical or biological intolerance were considered uncontrolled and ketoconazole was stopped. None of our patients received sucralfate or acidlowering agents during the period of treatment by ketoconazole, as stomach acidity is required for dissolution and absorption of the treatment. In patients with follow-up superior or equal to 36 months, dual energy X-ray absorptiometry was performed at the end of the treatment and compared with the pre-treatment evaluation. When ketoconazole was given awaiting possible later visualization of an intrasellar lesion, MRI was performed at 3-month and then 6-month intervals until treatment was stopped.

Statistical analysis was managed with SPSS version 13.0 (SPSS Inc., Chicago, IL, USA) for Windows. Comparison of means was evaluated with Student's $t$-test, and one-way ANOVA where possible. All statistical tests were two-tailed and $P<0.05$ was considered significant.

\section{Results}

Thirty-eight patients were included in this retrospective study (individual data reported in Table 1). Reasons for initiation of ketoconazole treatment were as follows: unsuccessful pituitary surgery ( $n=17$ patients); lack of image of adenoma on pituitary MRI ( $n=15$ patients); refusal (1 patient) or contraindication ( 1 patient) of surgery; and awaiting antisecretory efficacy of Gamma Knife radiosurgery (4 patients). Indeed, 21 patients were in the 'No pituitary surgery group' as they were treated with ketoconazole as a primary treatment and 17 in the 'After pituitary surgery group'. No patient was lost to follow-up. 
Table 1 Individual data of the 33 patients treated with ketoconazole (excluding the 5 patients with immediate cessation of treatment because of intolerance). Control of the disease was defined by normalization of 24-h urinary free cortisol. Maximal dose in mg/day.

\begin{tabular}{|c|c|c|c|c|c|c|}
\hline Patient & Sex/age & Group & Reason for treatment & Maximal dose & Outcome & Follow-up (months) \\
\hline 1 & $\mathrm{~F} / 42$ & Surgery & Unsuccessful surgery & 200 & Controlled & 72 \\
\hline 2 & $F / 32$ & No surgery & No MRI image & 400 & Controlled $^{a}$ & 12 \\
\hline 3 & $F / 66$ & Surgery & Unsuccessful surgery & 400 & Controlled & 30 \\
\hline 4 & $F / 73$ & No surgery & No MRI image & 400 & Controlled $^{\mathrm{a}}$ & 12 \\
\hline 5 & $F / 64$ & Surgery & Unsuccessful surgery & 400 & Controlled & 36 \\
\hline 6 & $F / 26$ & Surgery & Unsuccessful surgery & 400 & Controlled & 12 \\
\hline 7 & $F / 43$ & No surgery & No MRI image & 400 & Controlled & 12 \\
\hline 8 & $F / 39$ & Surgery & Unsuccessful surgery & 400 & Controlled & 12 \\
\hline 9 & $\mathrm{~F} / 50$ & Surgery & Unsuccessful surgery & 400 & Controlled & 18 \\
\hline 10 & $F / 33$ & No surgery & No MRI image & 400 & Controlled $^{\mathrm{a}}$ & 12 \\
\hline 11 & $F / 55$ & No surgery & No MRI image & 600 & Controlled $^{a}$ & 30 \\
\hline 12 & $\mathrm{~F} / 72$ & No surgery & GK latency & 600 & Controlled & 12 \\
\hline 13 & $F / 47$ & Surgery & GK latency & 600 & Controlled & 24 \\
\hline 14 & $F / 32$ & Surgery & Unsuccessful surgery & 600 & Controlled & 18 \\
\hline 15 & $\mathrm{~F} / 50$ & Surgery & Unsuccessful surgery & 800 & Controlled & 12 \\
\hline 16 & $\mathrm{~F} / 36$ & No surgery & No MRI image & 1000 & Controlled $^{\mathrm{a}}$ & 30 \\
\hline 17 & $F / 36$ & Surgery & Unsuccessful surgery & 1000 & Controlled & 60 \\
\hline 1 & $\mathrm{M} / 58$ & No surgery & No MRI image & 600 & Uncontrolled $^{\mathrm{b}}$ & 3 \\
\hline 2 & $F / 39$ & No surgery & No MRI image & 600 & Uncontrolled & 2 \\
\hline 3 & $\mathrm{M} / 52$ & No surgery & No MRI image & 600 & Uncontrolled & 12 \\
\hline 4 & $\mathrm{~F} / 50$ & Surgery & Unsuccessful surgery & 600 & Uncontrolled & 30 \\
\hline 5 & $F / 26$ & No surgery & Surgery refused & 800 & Uncontrolled & 1 \\
\hline 6 & $F / 24$ & No surgery & No MRI image & 800 & Uncontrolled $^{\mathrm{b}}$ & 36 \\
\hline 7 & $F / 58$ & No surgery & No MRI image & 800 & Uncontrolled & 6 \\
\hline 8 & $F / 26$ & No surgery & No MRI image & 1000 & Uncontrolled & 6 \\
\hline 9 & $F / 44$ & Surgery & GK latency & 1000 & Uncontrolled & 3 \\
\hline 10 & $F / 42$ & No surgery & No MRI image & 1000 & Uncontrolled & 1 \\
\hline 11 & $F / 29$ & Surgery & Unsuccessful surgery & 1000 & Uncontrolled $^{\mathrm{b}}$ & 3 \\
\hline 12 & $\mathrm{M} / 37$ & Surgery & GK latency & 1000 & Uncontrolled $^{\mathrm{b}}$ & 24 \\
\hline 13 & $\mathrm{M} / 55$ & Surgery & Unsuccessful surgery & 1000 & Uncontrolled $^{\mathrm{b}}$ & 24 \\
\hline 14 & $\mathrm{M} / 30$ & Surgery & Unsuccessful surgery & 1000 & Uncontrolled & 6 \\
\hline 15 & $\mathrm{~F} / 34$ & No surgery & No MRI image & 1200 & Uncontrolled & 1 \\
\hline 16 & $F / 18$ & Surgery & Unsuccessful surgery & 1200 & Uncontrolled & 6 \\
\hline
\end{tabular}

aO Outcome: patient for whom a pituitary adenoma could be visualized after ketoconazole treatment.

${ }^{\mathrm{b}}$ Patient with recurrence of hypercortisolism during ketoconazole treatment.

Ketoconazole was stopped in the first week of treatment in five patients $(13 \%)$ because of clinical (five patients with nausea and diarrhea) or biological intolerance (one patient, fivefold increasing of $\gamma$-GT with normal ASAT and ALAT). All of these patients had initiation of treatment with $200 \mathrm{mg} /$ day of ketoconazole. The remaining 33 patients were thus treated on a long-term basis by ketoconazole.

With a mean follow-up of 22.6 months, 17 patients were controlled ( $51.5 \%$ of those treated long term); doses of ketoconazole varied from 200 to $1000 \mathrm{mg} /$ day (mean $529 \mathrm{mg}$ /day). On an intention to treat basis, $44.7 \%$ of cases had thus normalized their UFC. Control of the disease was observed during the first month in eight patients and at 3 months after dose titration in nine patients.

The 17 biologically controlled patients also presented clinical regression of signs of hypercortisolism including lowering of blood pressure and loss of weight (mean loss: 1-2 $\mathrm{kg} 3$ months after initiation of treatment, $5 \mathrm{~kg}$ 1 year after initiation of treatment). Blood pressure was normal in all controlled patients 3-6 months after initiation of ketoconazole. Mean systolo-diastolic blood pressure before ketoconazole treatment under anti- hypertensive treatment was $148 / 105 \mathrm{mmHg}$; mean systolo-diastolic blood pressure after 3-6 months ketoconazole treatment and the same anti-hypertensive drugs was 115/85 mmHg. However, anti-hypertensive drugs were not stopped despite blood pressure control in most of the patients, and none of the five patients in whom anti-hypertensive treatment was stopped had normalized blood pressure (anti-hypertensive drugs were reintroduced at the same dose).

In the five diabetic patients (they all belonged to the 'controlled group'), metabolic control on the basis of blood glucose and glycosylated hemoglobin (HbAlc) monitoring was improved. Two of the patients were treated by insulin: in the first one, the dose of insulin decreased from 160 to 140 units per day and $\mathrm{HbA} 1 \mathrm{c}$ fell from 11.5 to $8 \%$ after 6 months of ketoconazole; in the second one, the dose of insulin fell from 90 to 60 units per day and HbAlc fell from 9 to $7.8 \%$ after 6 months of ketoconazole. The three other patients were treated with oral antidiabetic drugs (metformin alone or in combination with sulfonylurea). Antidiabetic treatment was not modified, but a $0.5-1 \%$ decrease in $\mathrm{HbAlc}$ was observed after 6-12 months of ketoconazole. One patient who had severe heart failure 
had a marked regression of cardiac signs, with a drastic decrease of heart-protective treatments. In the three patients who were followed-up for more than 36 months, absorptiometry showed severe osteoporosis at the time of CD diagnosis: two patients presented with osteopenia at the end of the treatment (36 and 60 months after initiation) and one patient had normal absorptiometry according to her age 72 months after initiation of treatment.

In contrast, 16 patients $(42.3 \%$ of the total cohort, $48.5 \%$ of those treated long term), treated for a mean period of 10 months with a mean dose of $890 \mathrm{mg} /$ day (varying from 600 to $1200 \mathrm{mg} /$ day), were uncontrolled at the end of the follow-up: five of them had initially been controlled, for a period of 3 months (two patients), 2 years (two patients), and 3 years (one patient), at doses varying from 600 to $1000 \mathrm{mg} /$ day.

Of the 16 uncontrolled patients, 8 presented a significant decrease in UFC: 5 of them normalized high blood pressure without modification of their antihypertensive therapy (patients $2,6,7,12$, and 13 of the uncontrolled group). From the other eight patients with unchanged UFC, the blood pressure status was not modified including three patients with normal blood pressure at initiation of ketoconazole treatment (patients 1,4 , and 5 of the uncontrolled group). Half of the 16 uncontrolled patients also displayed clinical regression of signs of hypercortisolism with mean loss of weight similar to that of controlled patients.

Initial hormonal levels were not predictive factors of remission: initial 24-h UFC, UFC percent decrease at 1 and 3 months, 0800 or $0000 \mathrm{~h} \mathrm{ACTH}$ and cortisol were not statistically different between controlled and uncontrolled patients (Table 2). None of our male patients were in the group of controlled patients. Doses of ketoconazole were obviously higher in uncontrolled patients, as they were systematically increased when there was no initial antisecretory efficacy. As shown in Fig. 1A and B, no clear dose-response relationship was found since higher doses were not systematically correlated with lower hormonal levels. We also tried to identify predictive factors in our population after exclusion of the five patients who ceased ketoconazole in the first week. However, none of the study parameters appeared to be associated with remission or therapeutic escape.

Ketoconazole was similarly efficacious in normalizing hormonal levels in the 'No pituitary surgery group' ( $n=7,44 \%$ cases controlled) or in the 'After pituitary surgery group' $(n=10,59 \%$ cases controlled). Followup was significantly lower in the former than in the latter group, as ketoconazole was stopped in the patients primarily treated with ketoconazole when an adenoma became visible on MRI. There was no significant difference between both groups in terms of age, sex, or initial hormonal levels (Table 3).

Except for the five patients who discontinued ketoconazole in the first week, no other patient stopped treatment during follow-up because of adverse effects. Adverse effects were indeed rare: three patients had a moderate increase of $\gamma$-GT at initiation of therapy (not exceeding two- to threefold the upper limit of normal), spontaneously regressive at 3 months; two uncontrolled patients presented clinical intolerance (nausea, diarrhea) when increasing dose to $1200 \mathrm{mg} /$ day; and one uncontrolled patient presented biological intolerance (eightfold the upper limit of normal of ASAT and ALAT) when increasing dose to $1200 \mathrm{mg} /$ day. The symptoms subsided after dose was decreased to $1000 \mathrm{mg} /$ day. It is important to note that no adrenal insufficiency or increase in size of previously visible lesions was observed.

Finally, ketoconazole was discontinued for a number of reasons: in one patient because of efficacy of Gamma Knife radiosurgery; in one patient surgery was decided because she wanted to be pregnant and ketoconazole is contraindicated during pregnancy; in four patients surgically treated with bilateral adrenalectomy after prolonged treatment ( $4-5$ years) with ketoconazole and no adenoma on MRI; and interestingly in five patients surgically treated because of the later visualization of an adenoma on MRI after treatment (12-30 months after initiation of ketoconazole) although no lesion was visible on the initial MRI (Fig. 2).

Table 2 Comparison between controlled $(n=17)$ and uncontrolled $(n=16)$ patients in 33 patients treated with ketoconazole. Control of the disease was defined by normalization of 24-h urinary free cortisol. Extreme values are represented between brackets. Sex ratio is presented as number of female $(F) /$ number of male $(M)$. Number of patients in the 'No pituitary surgery group' $(S-)$ /number of patients in the 'After pituitary surgery group' $(\mathrm{S}+)$. Percentage indicates the proportion of patients in each subgroup.

\begin{tabular}{llll}
\hline & Controlled & Uncontrolled & $P$ \\
\hline No. of patients & $17(51 \%)$ & $16(49 \%)$ & $\mathrm{NS}$ \\
Mean age (years) & $47.1(26-73)$ & $38.5(18-58)$ & $11 \mathrm{~F} / 5 \mathrm{M}$ \\
Sex ratio (F/M) & $17 \mathrm{~F} / 0 \mathrm{M}$ & $9 \mathrm{~S}-/ 7 \mathrm{~S}+$ & $\mathrm{NS}$ \\
No surgery group (S-)/after surgery group (S+) & $7 \mathrm{~S}-/ 10 \mathrm{~S}+$ & $61.4(17-149)$ & $\mathrm{NS}$ \\
ACTH 0800 h pg/ml & $67(8-172)$ & $65.1(11-190)$ & $\mathrm{NS}$ \\
ACTH 0000 h pg/ml & $62(25-100)$ & $628(141-955)$ & $\mathrm{NS}$ \\
Cortisol 0800 h nmol/d & $660(269-1270)$ & $513(301-960)$ & $\mathrm{NS}$ \\
Cortisol 0000 h nmol/d & $535(135-1100)$ & $2409(287-12500)$ & $\mathrm{NS}$ \\
Initial UFC nmol/d & $1560(248-16700)$ & $10(1-36)$ & $<0.05$ \\
Follow-up (months) & $22.6(6-72)$ & & \\
\hline
\end{tabular}

UFC, Urinary free cortisol. $P<0.05$ was considered significant; NS, non-significant. 

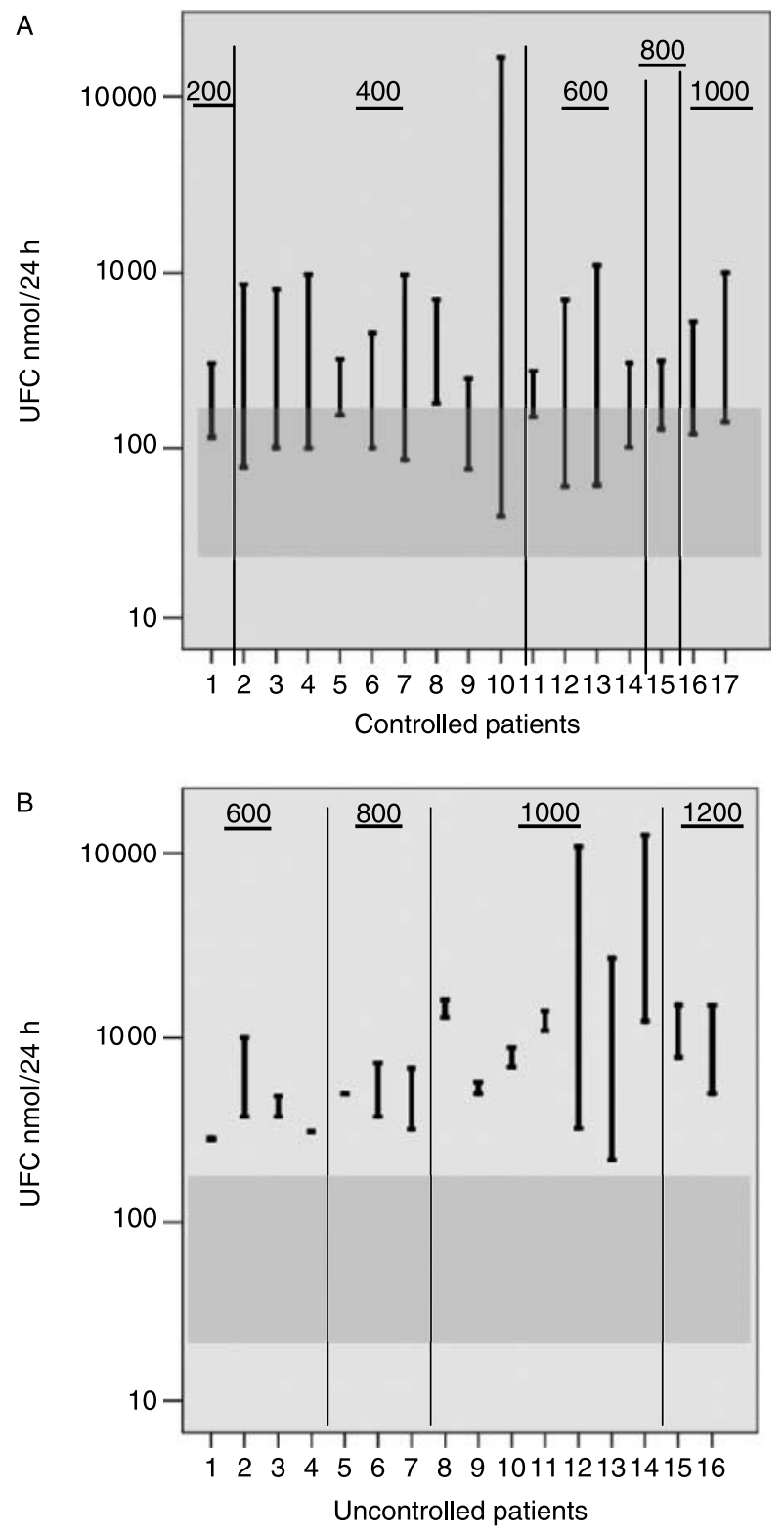

Figure 1 Urinary free cortisol ( $\mathrm{nmol} / 24 \mathrm{~h}$ ) before initiation of and after the last evaluation on ketoconazole in Cushing's disease patients with controlled (A) or uncontrolled (B) hypercortisolism. In vertical bars, the upper point represents the initial level of urinary free cortisol (UFC), the lower point represents the final level of UFC after treatment with ketoconazole. Numbers in the upper part of the figure represent dose of ketoconazole in $\mathrm{mg} /$ day. Grey zone represents normal interval of urinary free cortisol (40-240 nmol/24 h). Remission was defined by normalization of urinary free cortisol.

\section{Discussion}

Transsphenoidal surgery remains the first-line treatment of $\mathrm{CD}(1)$. However, the rate of remission varies with the type of adenoma, estimated to be around $80 \%$ in microadenomas and about $50 \%$ in macroadenomas. Recurrence can be observed in $20-30 \%$ of cases, particularly in case of cavernous sinus invasion $(2-4,32-34)$.
Table 3 Comparison of the results of ketoconazole treatment in 'No pituitary surgery group' ( $\mathrm{S}-$ ) or 'After pituitary surgery group' $(\mathrm{S}+)$. Control of the disease was defined by normalization of 24-h urinary free cortisol. Extreme values are represented between brackets. Sex ratio: number of female (F)/number of male (M). Percentage indicates the proportion of patients in each subgroup.

\begin{tabular}{lllr}
\hline & $\begin{array}{l}\text { No pituitary } \\
\text { surgery group }\end{array}$ & $\begin{array}{l}\text { After pituitary } \\
\text { surgery group }\end{array}$ & $\boldsymbol{P}$ \\
\hline No. of patients & $16(49 \%)$ & $17(51 \%)$ & \\
Mean age (year) & $44(24-73)$ & $42(18-66)$ & $\mathrm{NS}$ \\
Sex ratio (F/M) & $14 \mathrm{~F} / 2 \mathrm{M}$ & $14 \mathrm{~F} / 3 \mathrm{M}$ & $\mathrm{NS}$ \\
ACTH 0800 h & $54.4(8-172)$ & $76(17-149)$ & $\mathrm{NS}$ \\
ACTH 0000 h & $53.8(11-93)$ & $73(17-190)$ & $\mathrm{NS}$ \\
Cortisol 0800 h & $652(141-1270)$ & $637(269-908)$ & $\mathrm{NS}$ \\
Cortisol 0000 h & $547(135-1100)$ & $501(186-960)$ & $\mathrm{NS}$ \\
Initial 24 h UFC & $1792(275-16700)$ & $2124(248-12500)$ & $\mathrm{NS}$ \\
Follow-up & $9.5(1-30)$ & $22.9(3-72)$ & $<0.05$ \\
(months) & $7(44 \%)$ & $10(59 \%)$ & $\mathrm{NS}$ \\
Controlled & & & \\
\hline
\end{tabular}

UFC, urinary free cortisol. $P<0.05$ was considered significant; NS, nonsignificant.

The imidazole derivative ketoconazole reduces cortisol levels by inhibition of a variety of cytochrome P450 enzymes (19). In addition to its anti-steroidogenic effects, ketoconazole may also have extra-adrenal actions (as it was found to behave as a glucocorticoid receptor antagonist and to impair ACTH release in vitro) (21). With doses of ketoconazole varying from 200 to $1200 \mathrm{mg} /$ day, about $50 \%$ of our patients with CD, treated as a first or as an adjunctive treatment were controlled at last evaluation, and only $15 \%$ revealed recurrence of hypercortisolism.

To our knowledge, this study currently represents the largest published about ketoconazole in CD. Earlier studies were based on fewer patients $(23,24,26$, 35-37), including one on 28 patients with $\mathrm{CD}$, previously treated by conventional radiotherapy (30). In most cases, doses of ketoconazole were not increased beyond $1200 \mathrm{mg} /$ day. Indeed, comparison with other series from the literature is difficult (Table 4): control of the disease varies from 0 to $100 \%$ of cases, but most of the studies had a low number of patients (between two and seven patients) (15). The only study with 28 patients, which described $93 \%$ of patients as controlled is biased by the fact that all patients had previously been treated with conventional radiotherapy, making a correct evaluation of ketoconazole alone impossible (30). Other medical treatments (mitotane (11-13), metyrapone $(14,38,39)$, RU486 (40), bromocriptine $(15,41)$, etomidate $(42,43)$, peroxysome proliferator activator receptor (PPAR)- $\gamma$ agonists (16-18)) or non-medical treatments (conventional radiotherapy $(6,7)$, Gamma Knife Radiosurgery (8-10), or bilateral adrenalectomy (5)) have been proposed as a treatment of $\mathrm{CD}$, but they all have specific side effects, or were not evaluated in a sufficient number of patients (see Table 5 for comparative data). 


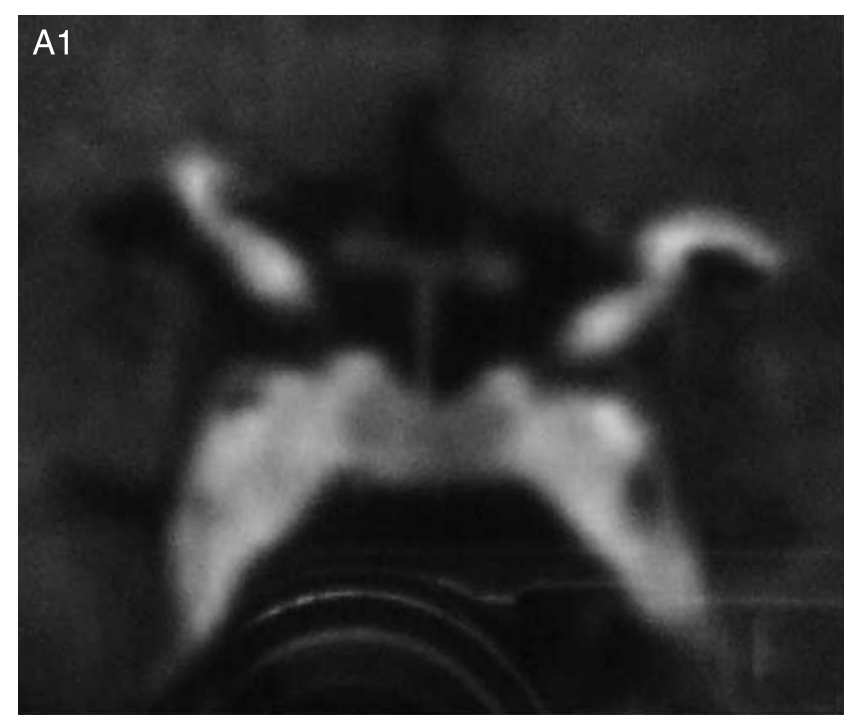

B1

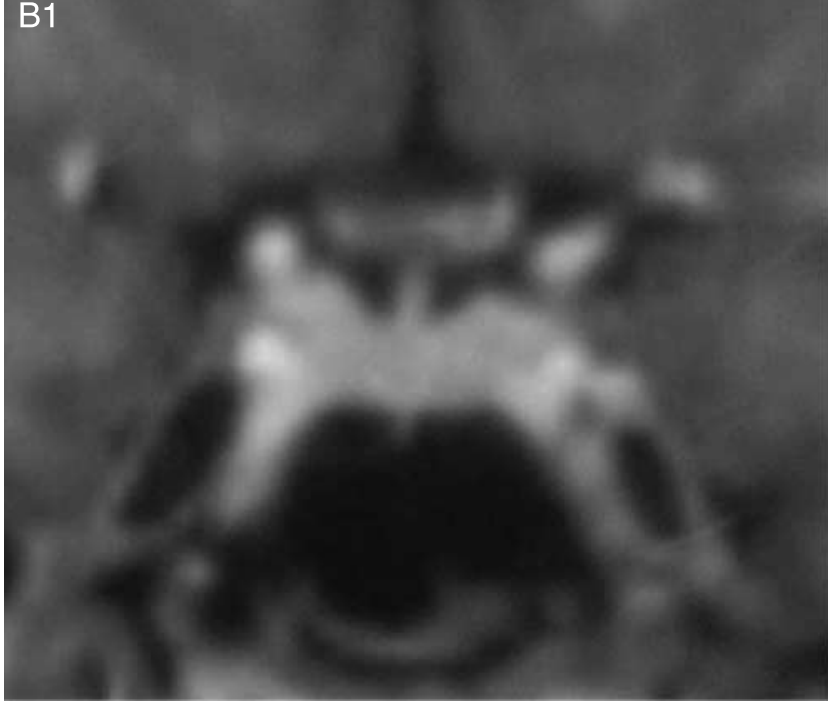

A2

$\mathrm{B} 2$
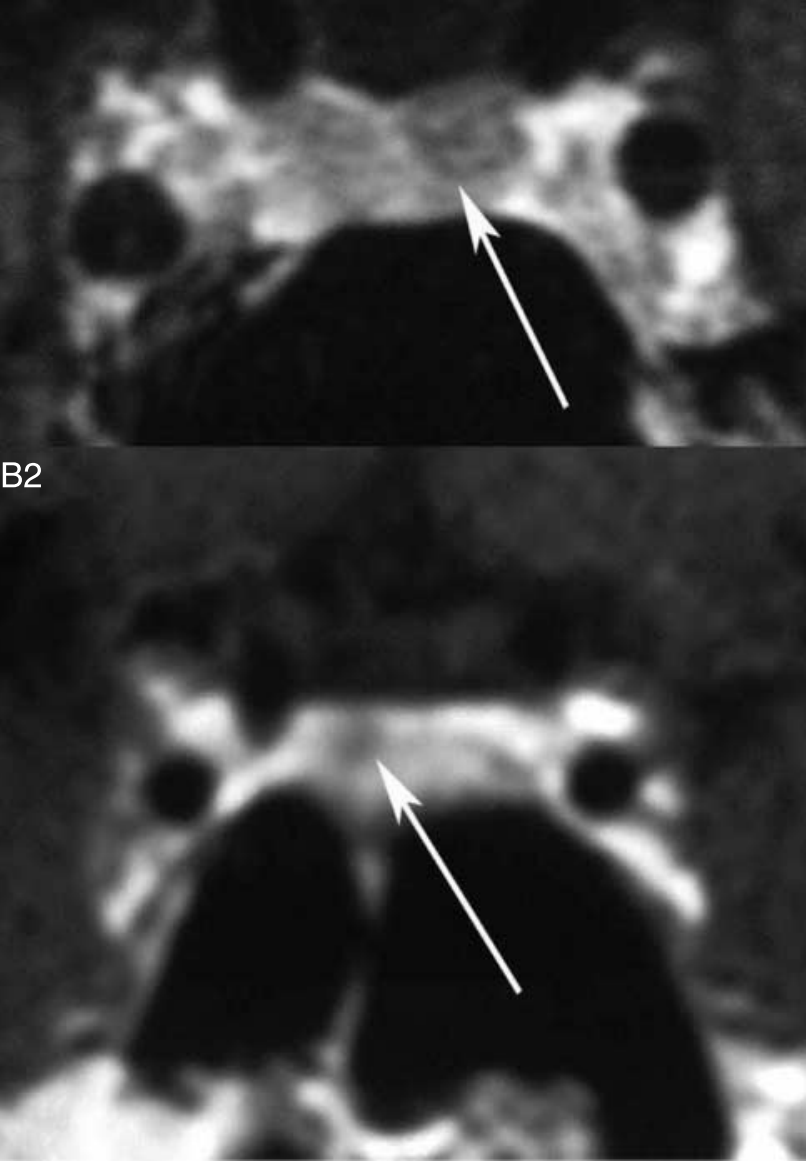

Figure 2 Pituitary MRI (sagittal, T1-weighted sequence after gadolinium injection) before and after ketoconazole treatment, disclosing the delayed visualization of an adenoma. (A1) Before ketoconazole treatment, heterogeneous pituitary without evident image of an adenoma. (A2) After 30 months of ketoconazole treatment, visualization of a left latero-sellar microadenoma. (B1) Before ketoconazole treatment, lack of pituitary adenoma image. (B2) After 12 months of treatment, a right latero-sellar microadenoma is visualized. In both cases, surgery was performed and allowed histological confirmation of the diagnosis and remission.

Interestingly, we did not find any significant difference in any of the parameters studied between patients in the 'No pituitary surgery group' and those in the 'After pituitary surgery group'. This point is particularly important in case of lack of visible adenoma on MRI. In this respect, our study illustrates the potential interest of a 'wait and see' attitude, which consists of giving ketoconazole first, and waits for the adenoma to possibly be visualized on MRI during subsequent followup. Indeed, in 5 out of the 15 patients without evident image on MRI, an adenoma could eventually be visualized after prolonged treatment (12-30 months), and these 5 patients were finally cured by transsphenoidal surgery. Although our data do not allow the claim that such a strategy is more effective than surgical exploration of the pituitary, they suggest that it represents a therapeutic option that may facilitate a second-line surgical approach.

No predictive factor of remission could be identified. In particular, initial hormonal levels and type of adenoma were not significantly different between patients controlled or not. Interestingly, none of our male patients were in the group of controlled patients. Although this difference was statistically significant, we did not manage to find any convincing hypothesis to explain this point. To our knowledge, gender differences in sensitivity to ketoconazole have never been described in CD. Moreover, among uncontrolled patients, three male patients with 
Table 4 Efficacy of ketoconazole in previously published reports of the literature. Only studies including more than five patients are reported.

\begin{tabular}{lllll}
\hline Author & $\begin{array}{l}\text { Mean } \\
\text { Patients } \\
\text { number }\end{array}$ & $\begin{array}{l}\text { Controlled } \\
\text { follow-up } \\
\text { (months) }\end{array}$ & $\begin{array}{l}\text { Side } \\
\text { patients }\end{array}$ & $\begin{array}{l}\text { Sidfects } \\
\text { eff) }\end{array}$ \\
\hline Sonino (30) & $28^{\text {a }}$ & 7 & 93 & 29 \\
Loli (23) & 6 & 8 & 100 & 0 \\
Cerdas (35) & 6 & 1 & 100 & 40 \\
Mortimer (28) & 8 & 0.5 & 100 & 25 \\
McCance (36) & 6 & 0.5 & 83 & 50 \\
Engelhardt (37) & 7 & 0.5 & 14 & 0 \\
Our study & 38 & 22.6 & 51.5 & 29 \\
All studies & 99 & 5.7 & 74 & 25 \\
\hline
\end{tabular}

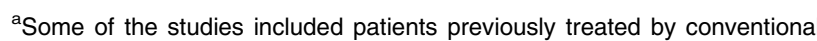
radiotherapy.

markedly elevated baseline UFC values (patients 12, 13, and 14) experienced a drastic fall in UFC reaching values approaching the upper limit of normal in two cases. As a consequence, male patients cannot be considered as nonresponders to ketoconazole therapy.

The importance of the 3 months evaluation is worth underlying: all of our patients in remission were controlled within the first 3 months of treatment, not necessarily with the highest dose of ketoconazole. This means that ketoconazole is unlikely to be effective in case of uncontrolled hypercortisolism 3 months after the initiation of the treatment, if the dose was sufficiently increased. No predictive factor of later relapse of the disease could be individualized.

Five of our patients stopped the treatment during the first week because of clinical or biological intolerance, despite the use of a low dose at initiation of treatment ( $200 \mathrm{mg} /$ day). No other patient stopped treatment during later follow-up. However, abnormal liver function tests were observed in one patient when ketoconazole was given at $1200 \mathrm{mg} /$ day; this patient was not controlled and treatment had to be stopped anyway. All other adverse effects were transient and observed when increasing the dose of ketoconazole during the first week. Comparison with previous series is difficult as other treatments were sometimes associated. In the study by Sonino et al. $(n=28$ patients), ketoconazole was stopped during the first week for allergic reaction and acute liver toxicity in two patients ( $7 \%$ vs $13 \%$ in our series) (30). Other series did not evaluate enough patients to draw any firm conclusion. Few case reports described fatal hepatic cytolysis with ketoconazole (44-46). It is also necessary to stress that, as in another report based on three patients (31), three of our patients were treated for 60-72 months, with controlled hypersecretion and lack of adverse effects. This point confirms that intolerance is more likely to appear initially or at dose increase than during prolonged treatment at a stable dose. Close clinical and biological follow-up is necessary at titration steps on a weekly/ monthly basis, while follow-up during long-term treatment with unchanged dose requires much less frequent controls. No Nelson's syndrome was observed in our study although secondary visualization of previously non-visible lesions might be considered as an equivalent of Nelson's syndrome in terms of mechanism.

To conclude, with $50 \%$ effectiveness and relatively few adverse effects, ketoconazole appeared as a valuable treatment in CD. When control of the disease was observed, it always occurred during the first 3 months of treatment. Side effects mainly occurred in the first week after initiation of treatment or in the case of dose increase, which makes it necessary to implement strict follow-up evaluations at each titration steps. In comparison with many other treatments of $\mathrm{CD}$, ketoconazole also has the advantage of being less expensive. It can also be useful in case of lack of evident image on MRI, waiting for the adenoma to become visible to possibly allow easier secondary surgical removal. In such cases, if hypercortisolism is controlled, ketoconazole can be maintained during a prolonged period (up to 72 months in our study) without adverse effects.

Table 5 Comparison of different modalities of treatment of Cushing's disease in comparison with ketoconazole, based on the literature reports.

\begin{tabular}{|c|c|c|c|}
\hline Treatment & Main mechanism of action & $\begin{array}{l}\text { Controlled } \\
\text { patients }\end{array}$ & Main adverse effect \\
\hline Op'DDD (11-13) & 11- $\beta$-hydroxylase inhibition & $30-100 \%{ }^{a}$ & Hypercholesterolemia, liver alterations \\
\hline Metyrapone $(14,38,39)$ & $11-\beta$-hydroxylase inhibition & $20-100 \%^{\mathrm{a}}$ & Hirsutism \\
\hline Bromocriptine $(15,41)$ & Blockade of dopamine receptors & $0-66 \%$ & Hypotension, nausea \\
\hline Mifepristone $(15,40)$ & Glucocorticoid antagonist & $50-80 \%{ }^{b}$ & Nausea, asthenia \\
\hline Etomidate $(42,43)$ & 11- $\beta$-hydroxylase inhibition & Case reports & \\
\hline PPAR- $\gamma$ agonists $(16-18)$ & Bad defined & $0-43 \%$ & Edema \\
\hline Conventional radiotherapy $(6,7)$ & & $60-90 \%$ & Hypopituitarism \\
\hline Gamma Knife Radiosurgery (8-10) & & $50-100 \%$ & Hypopituitarism \\
\hline Bilateral adrenalectomy $(5,15)$ & & $84-91 \%$ & Nelson's syndrome \\
\hline Transsphenoidal surgery $(1-4,32-34)$ & & $40-90 \%$ & \\
\hline Ketoconazole & Cytochrome P450 enzymes inhibition & $15-100 \%^{\mathrm{a}}$ & Liver function alterations \\
\hline
\end{tabular}

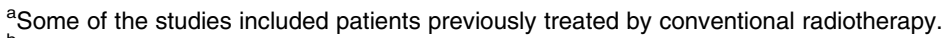

${ }^{b}$ Only few patients were treated by mifepristone making difficult a correct evaluation of this treatment. 


\section{References}

1 Arnaldi G, Angeli A, Atkinson AB, Bertagna X, Cavagnini F, Chrousos GP, Fava GA, Findling JW, Gaillard RC, Grossman AB, Kola B, Lacroix A, Mancini T, Mantero F, Newell-Price J, Nieman LK, Sonino N, Vance ML, Giustina A \& Boscaro M. Diagnosis and complications of Cushing's syndrome: a consensus statement. Journal of Clinical Endocrinology and Metabolism 2003 88 5593-5602.

2 Laws ER, Reitmeyer M, Thapar K \& Vance ML. Cushing's disease resulting from pituitary corticotrophic microadenoma. Treatment results from transsphenoidal microsurgery and gamma knife radiosurgery. Neuro-Chirurgie $2002 \mathbf{4 8} 294-299$.

3 Bochicchio D, Losa M \& Buchfelder M. Factors influencing the immediate and late outcome of Cushing's disease treated by transsphenoidal surgery: a retrospective study by the European Cushing's Disease Survey Group. Journal of Clinical Endocrinology and Metabolism 199580 3114-3120.

4 Burke CW, Adams CB, Esiri MM, Morris C \& Bevan JS. Transsphenoidal surgery for Cushing's disease: does what is removed determine the endocrine outcome? Clinical Endocrinology 199033 525-537.

5 Assie G, Bahurel H, Coste J, Silvera S, Kujas M, Dugue MA, Karray F, Dousset B, Bertherat J, Legmann P \& Bertagna X. Corticotroph tumor progression after adrenalectomy in Cushing's disease: a reappraisal of Nelson's syndrome. Journal of Clinical Endocrinology and Metabolism 200792 172-179.

6 Estrada J, Boronat M, Mielgo M, Magallon R, Millan I, Diez S, Lucas $\mathrm{T} \&$ Barcelo B. The long-term outcome of pituitary irradiation after unsuccessful transsphenoidal surgery in Cushing's disease. New England Journal of Medicine 1997336 172-177.

7 Sonino N. Zielezny M, Fava GA, Fallo F \& Boscaro M. Risk factors and long-term outcome in pituitary-dependent Cushing's disease. Journal of Clinical Endocrinology and Metabolism $1996 \mathbf{8 1}$ 2647-2652.

8 Castinetti F, Nagai M, Dufour H, Kuhn JM, Morange I, Jaquet P, Conte-Devolx B, Regis J \& Brue T. Gamma knife radiosurgery is a successful adjunctive treatment in Cushing's disease. European Journal of Endocrinology 2007156 91-98.

9 Laws ER, Sheehan JP, Sheehan JM, Jagnathan J, Jane JA, Jr \& Oskouian R. Stereotactic radiosurgery for pituitary adenomas: a review of the literature. Journal of Neuro-Oncology 2004 69 257-272.

10 Brada M, Ajithkumar TV \& Minniti G. Radiosurgery for pituitary adenomas. Clinical Endocrinology 200461 531-543.

11 Luton JP, Mahoudeau JA, Bouchard P, Thieblot P, Hautecouverture M, Simon D, Laudat MH, Touitou Y \& Bricaire H. Treatment of Cushing's disease by O,p'DDD. Survey of 62 cases. New England Journal of Medicine $1979 \mathbf{3 0 0}$ 459-464.

12 Robinson BG, Hales IB, Henniker AJ, Ho K, Luttrell BM, Smee IR \& Stiel JN. The effect of $o, p^{\prime}$-DDD on adrenal steroid replacement therapy requirements. Clinical Endocrinology 198727 437-444.

13 Cooper PR \& Shucart WA. Treatment of Cushing's disease with o,p'-DDD. New England Journal of Medicine 1979301 48-49.

14 Verhelst IA, Trainer PJ, Howlett TA, Perry L, Rees LH, Grossman AB, Wass JA \& Besser GM. Short and long-term responses to metyrapone in the medical management of 91 patients with Cushing's syndrome. Clinical Endocrinology 199135 $169-178$

15 Miller JW \& Crapo L. The medical treatment of Cushing's syndrome. Endocrine Reviews 199314 443-458.

16 Ambrosi B, Dall'Asta C, Cannavo S, Libe R, Vigo T, Epaminonda P, Chiodini I, Ferrero S, Trimarchi F, Arosio M \& Beck-Peccoz P. Effects of chronic administration of PPAR-gamma ligand rosiglitazone in Cushing's disease. European Journal of Endocrinology 2004151 173-178.

17 Cannavo S, Arosio M, Almoto B, Dall'Asta C \& Ambrosi B. Effectiveness of long-term rosiglitazone administration in patients with Cushing's disease. Clinical Endocrinology 200563 118-119.
18 Barbaro D, Lapi P, Orsini P, Pasquini C \& Ciaccio S. Pioglitazone treatment in Cushing's disease. Journal of Endocrinological Investigation 200528 388-389.

19 Sonino N. The use of ketoconazole as an inhibitor of steroid production. New England Journal of Medicine 1987317 812-818.

20 Feldman D. Ketoconazole and other imidazole derivatives as inhibitors of steroidogenesis. Endocrine Reviews 19867 409-420.

21 Loose DS, Stover EP \& Feldman D. Ketoconazole binds to glucocorticoid receptors and exhibits glucocorticoid antagonist activity in cultured cells. Journal of Clinical Investigation $1983 \mathbf{7 2}$ 404-408.

22 Pardes E, De Yampey JE, Moses DF \& De Nicola AF. Regulation of glucocorticoid receptors in human mononuclear cells: effects of glucocorticoid treatment, Cushing's disease and ketoconazole. Journal of Steroid Biochemistry and Molecular Biology 199139 233-238.

23 Loli P, Berselli ME \& Tagliaferri M. Use of ketoconazole in the treatment of Cushing's syndrome. Journal of Clinical Endocrinology and Metabolism $1986 \mathbf{6 3} 1365-1371$.

24 Tabarin A, Navarranne A, Guerin J, Corcuff JB, Parneix M \& Roger P. Use of ketoconazole in the treatment of Cushing's disease and ectopic ACTH syndrome. Clinical Endocrinology 1991 34 63-69.

25 Angeli A \& Frairia R. Ketoconazole therapy in Cushing's disease. Lancet 19851821.

26 Terzolo M, Panarelli M, Piovesan A, Torta M, Paccotti P \& Angeli A. Ketoconazole treatment in Cushing's disease. Effect on the circadian profile of plasma ACTH and cortisol. Journal of Endocrinological Investigation 198811 717-721.

27 Sonino N, Boscaro M, Merola G \& Mantero F. Prolonged treatment of Cushing's disease by ketoconazole. Journal of Clinical Endocrinology and Metabolism 198561 718-722.

28 Mortimer RH, Cannell GR, Thew CM \& Galligan JP. Ketoconazole and plasma and urine steroid levels in Cushing's disease. Clinical and Experimental Pharmacology and Physiology 1991 18 563-569.

29 Farwell AP, Devlin JT \& Stewart JA. Total suppression of cortisol excretion by ketoconazole in the therapy of the ectopic adrenocorticotropic hormone syndrome. American Journal of Medicine $1988 \mathbf{8 4}$ 1063-1066.

30 Sonino N, Boscaro M, Paoletta A, Mantero F \& Ziliotto D. Ketoconazole treatment in Cushing's syndrome: experience in 34 patients. Clinical Endocrinology 199135 347-352.

31 Chou SC \& Lin ID. Long-term effects of ketoconazole in the treatment of residual or recurrent Cushing's disease. Endocrine Journal 200047 401-406.

32 Arnott RD, Pestell RG, McKelvie PA, Henderson JK, McNeill PM \& Alford FP. A critical evaluation of transsphenoidal pituitary surgery in the treatment of Cushing's disease: prediction of outcome. Acta Endocrinologica 1990123 423-430.

33 Bakiri F, Tatai S, Aouali R, Semrouni M. Derome P, Chitour F \& Benmiloud M. Treatment of Cushing's disease by transsphenoidal, pituitary microsurgery: prognosis factors and long-term follow-up. Journal of Endocrinological Investigation 199619 572-580.

34 Vallette-Kasic S, Dufour H, Mugnier M, Trouillas J, Valdes-Socin H, Caron P, Morange S, Girard N, Grisoli F, Jaquet P \& Brue T. Markers of tumor invasion are major predictive factors for the long-term outcome of corticotroph microadenomas treated by transsphenoidal adenomectomy. European Journal of Endocrinology $2000143761-768$.

35 Cerdas S, Billaud L, Guilhaume B, Laudat MH, Bertagna X \& Luton JP. Short term effects of ketoconazole in Cushing's syndrome. Annales d'Endocrinologie 198950 489-496.

36 McCance DR, Hadden DR, Kennedy L, Sheridan B \& Atkinson AB. Clinical experience with ketoconazole as a therapy for patients with Cushing's syndrome. Clinical Endocrinology 198727 593-599.

37 Engelhardt D \& Weber MM. Therapy of Cushing's syndrome with steroid biosynthesis inhibitors. Journal of Steroid Biochemistry and Molecular Biology 199449 261-267.

38 Totani Y, Niinomi M. Takatsuki K. Oiso Y \& Tomita A. Effect of metyrapone pretreatment on adrenocorticotropin secretion 
induced by corticotropin-releasing hormone in normal subjects and patients with Cushing's disease. Journal of Clinical Endocrinology and Metabolism $1990 \mathbf{7 0} 798-803$.

39 Dickstein G, Lahav M, Shen-Orr Z, Edoute Y \& Barzilai D. Primary therapy for Cushing's disease with metyrapone. Journal of the American Medical Association 1986255 1167-1169.

40 Chu JW, Matthias DF, Belanoff J, Schatzberg A, Hoffman AR \& Feldman D. Successful long-term treatment of refractory Cushing's disease with high-dose mifepristone (RU 486). Journal of Clinical Endocrinology and Metabolism 200186 3568-3573.

41 Croughs RJ, Koppeschaar HP, van't Verlaat JW \& McNicol AM. Bromocriptine-responsive Cushing's disease associated with anterior pituitary corticotroph hyperplasia or normal pituitary gland. Journal of Clinical Endocrinology and Metabolism 198968 495-498.

42 Schulte HM, Benker G, Reinwein D, Sippell WG \& Allolio B. Infusion of low dose etomidate: correction of hypercortisolemia in patients with Cushing's syndrome and dose-response relationship in normal subjects. Journal of Clinical Endocrinology and Metabolism 199070 1426-1430.
43 Greening JE, Brain CE, Perry LA, Mushtaq I, Sales Marques J, Grossman AB \& Savage MO. Efficient short-term control of hypercortisolaemia by low-dose etomidate in severe paediatric Cushing's disease. Hormone Research 200564 140-143.

44 Klausner MA. Ketoconazole and hepatitis. Journal of the American Academy of Dermatology 199226 1028-1030.

45 Knight TE, Shikuma CY \& Knight J. Ketoconazole-induced fulminant hepatitis necessitating liver transplantation. Journal of the American Academy of Dermatology 199125 398-400.

46 Duarte PA, Chow CC, Simmons F \& Ruskin J. Fatal hepatitis associated with ketoconazole therapy. Archives of Internal Medicine $19841441069-1070$.

Received 15 October 2007

Accepted 16 October 2007 